研 究

炭素繊維強化 SiC 複合セラミックスの機械特性に及ばす炭素繊維への $\mathrm{SiC}$ 被覆の影響 (2)

$\begin{array}{lrr}\text { 吉田 } & \text { 秀人, 内藤 一成 } \\ \text { 宮田 昇, 山㟁 千丈 }\end{array}$

日本セメント研究所, $\mathbf{T} 135$ 江東区清澄1-2-23.

\title{
Influence of SiC Coating on the Mechanical Properties of Unidirectionally Reinforced Carbon-SiC Composites (2)
}

Hideto Yoshida, Kazunari Naito

Noboru Miyata and Chitake Yamagishi

\begin{abstract}
New Materials Research Department, Central Research Laboratory Nihon Cement Co., Ltd., 1-2-23 Kiyosumi Koto-ku, Tokyo 135.
\end{abstract}

$\mathrm{SiC}$ coated carbon fiber $\left(\mathrm{SiC} \cdot \mathrm{C}_{t}\right)$ and carbon fiber $\left(\mathrm{C}_{1}\right)$ were used to fabricate $\mathrm{SiC}$ composites reinforced with unidirectionally oriented carbon fibers $\left(\mathrm{C}_{\mathrm{i}} / \mathrm{SiC}\right.$ and $\left.\mathrm{SiC} \cdot \mathrm{C}_{t} / \mathrm{SiC}\right)$. Mechanical properties of $\mathrm{SiC} \cdot \mathrm{C}_{t} / \mathrm{SiC}$ composite differed much from those of $\mathrm{C}_{t} / \mathrm{SiC}$ composite. Flexural strengths at room temperature and $1450^{\circ} \mathrm{C}$ of $\mathrm{SiC} \cdot \mathrm{C}_{1} / \mathrm{SiC}$ composite are smaller than those of $\mathrm{C}_{t} / \mathrm{SiC}$ composite. On the othe hand, fracture energy of $\mathrm{SiC} \cdot \mathrm{C}_{1} / \mathrm{SiC}$ composite is larger than that of $\mathrm{C}_{1} / \mathrm{SiC}$ composite. It was considered that the difference of them was caused by changes of the interfacial strength between fiber and matrix in the composite.

\section{1 緒言}

前報")において，数千本の炭素緎維束の各表面に C V D 法で, 緻密で高純度なSiCを連続的にコーテ イングする方法を示した．このSiC被覆炭素瀻維 （以後 $\mathrm{SiC} \cdot \mathrm{C}_{\mathrm{t}}$ と称す）を用いて，炭素維維強化 $\mathrm{SiC}$ （以後 $\mathrm{SiC} \cdot \mathrm{C}_{t} / \mathrm{SiC}$ 称す）を作製すると，焼結過 程で織維と接触する部分のマトリックス成分は，

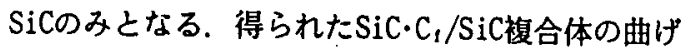
強度が，炭素瀻維をそのまま用いて作製した $\mathrm{C}_{t} / \mathrm{SiC}$ 複合体の強度より低くなることから, $\mathrm{SiC} \cdot \mathrm{C}_{t} / \mathrm{SiC}$ 複 合体の織維/マトリックス界面の特性は， $\mathrm{C}_{\mathrm{t}} / \mathrm{SiC}$ 複
合体と異なる特性を示すことが考えられる，そこで， 本報では， $\mathrm{C}_{t} / \mathrm{SiC}$ 機械特性に及ぼす界面特性の影 響を明らかにするため，界面特性が異なると考えら れるSiC·C $/ / \mathrm{SiC}$ 複合体と $\mathrm{SiC} \cdot \mathrm{C}_{2} / \mathrm{SiC}$ 複合体について, 曲げ強度，破壊エネルギー，破壊鞋性等の測定およ び破面観察を行い，両複合体の特性の違いを明らか にすることから，界面の役割について検討した．ま た前報で，曲げ強度が低かった $\mathrm{SiC} \cdot \mathrm{C}_{t} / \mathrm{SiC}$ 複合体の 改良法についても報告する。

2 試料作製, 評価方法 


\section{2. $1 \mathrm{SiC} \cdot \mathrm{C}_{t} / \mathrm{SiC}$ 作製}

炭素維維 $\left(C_{t}\right)$ およびSiC·C 方向宥素緁維強化SiC $\left(\mathrm{C}_{t} / \mathrm{SiC}\right.$ よびSiC· $\left.\mathrm{C}_{t} / \mathrm{SiC}\right)$ を作製した，焼結体の作製方法は，前報の通りであ るが，焼結温度は，前報の $1950^{\circ} \mathrm{C}$ に加え， $2000^{\circ} \mathrm{Cで}$ も実施した，焼結体は，研削後，切断して試験片

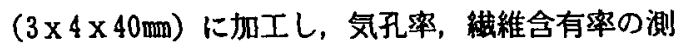
定並びに走查型電子顕微鏡（日立製 S-4000）によ る砤構造観察等を行った.

\section{2 機械特性評価}

$\mathrm{C}_{t} / \mathrm{SiC}$ 焼結体の破壊挙動を調べるため, $1450^{\circ} \mathrm{C}$ に おける高温曲げ強度および室温強度を測定した．ま た試料の応力集中源に対する破壊抵抗を調べるため， S EN B 法によりノッチを人れた試験片を用いて 3 点曲げ強度を測定した，絨維の含有率，曲げ強度お よび破壊靬性值の計算方法は，既報 ${ }^{2)}$ の通りである. なお，破壊エネルキーは，破填抵抗測定時に得ら れる荷重一变位曲線と变位軸の囲む面檟より破壊仕 事 $\left(U_{w 01}\right)$ を測定し，（1）式により求めた.

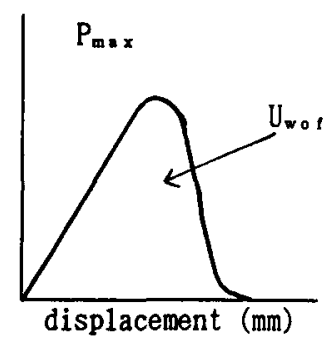

Fig.1 Measurement of fracture energy.

$$
\gamma=\frac{\mathrm{U}_{w 01}}{2(\mathrm{w}-\mathrm{a}) \cdot \mathrm{t}}
$$

$$
\begin{aligned}
& \gamma: \text { 破壊エネルギー Uwo1：破壊仕井 } \\
& \mathrm{w}: \text { 試験片幅 a : ノッチ深さ } \\
& \mathrm{t} \text { : 試験片厚さ }
\end{aligned}
$$

\section{3 実験䊅果及び考察}

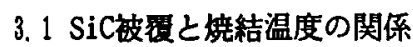

$\mathrm{C}_{t} / \mathrm{SiC}$ 複合体は，焼結温度をあげると，焼結時に

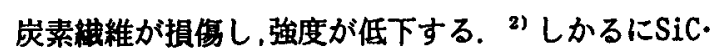
$\mathrm{C}_{t} / \mathrm{SiC}$ 複合体の曲け強度測定時の炭素耤維の引き抜 け状態をみると， $\mathrm{C} / \mathrm{SiC}$ 複合体に比へ檋䊒の引き
抜け長さは長く，引き拔けた織維の表面は滑らかで あり，繀維に損倁が見られなかった。

このことは， $\mathrm{SiC} \cdot \mathrm{C}_{t} / \mathrm{SiC}$ 複合体では， $\mathrm{C}_{t} / \mathrm{SiC}$ 複合 体の焼結温度に比へ，より高い温度で焼結させても 䄉維が劣化しない可能性を示している. そこで, 19 $50^{\circ} \mathrm{C}$ と $2000^{\circ} \mathrm{C}$ の焼結温度で $\mathrm{SiC} \cdot \mathrm{C}_{1} / \mathrm{SiC}$ 複合体を焼結 し，曲げ強度を比較した，Table 1 に両複合体の気 孔率，㵶維含有率 $\left(\mathrm{V}_{\mathrm{B}}\right)$ および曲げ強度の测定結 果を示す. Table1より, 雨複合体の気孔率がほぼ

Table 1 Characteristics and flexural strength of $\mathrm{SiC} \cdot \mathrm{C}_{\mathrm{f}} / \mathrm{SiC}$ composites sintered at $1950^{\circ}$ and $2000^{\circ} \mathrm{C}$.

\begin{tabular}{|c|c|c|c|}
\hline \multirow{2}{*}{ Characteristics } & \multicolumn{2}{|c|}{ Sintering. Temp. $\left({ }^{\circ} \mathrm{C}\right)$} \\
\cline { 2 - 4 } & 1950 & 2000 \\
\hline \multicolumn{2}{|c|}{ 0pen Porosity (\%) } & 8 & 6 \\
\hline \multicolumn{2}{|c|}{ Fiber Content (\%) } & 56 & 56 \\
\hline $\begin{array}{l}\text { Flexura1 } \\
\text { strength } \\
(\mathrm{MPa})\end{array}$ & Room temp. & 340 & 540 \\
\cline { 2 - 4 } & $1450^{\circ} \mathrm{C}$ & 540 & 720 \\
\hline
\end{tabular}

等しく，V、が同じことから，焼結温度を変えても ほぼ同じ焼結性を示す複合体が得られたと考えられ る.ここで, $2000^{\circ} \mathrm{C} て ゙$ 焼結したSiC·C $\mathrm{C}_{l} / \mathrm{SiC}$ 複合体の

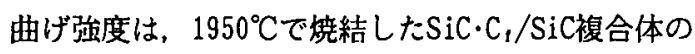
曲げ強度に比べ高くなり，期待どおり焼結温度を

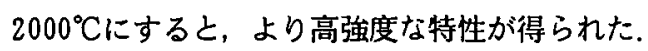

ここで,Fig. 2 に，曲げ強度測定時の荷重一変位 曲線を示す，両複合体の荷重一変位曲線を比較する と，類似の曲線を示し，最大荷重に達する時の変位 は，同じである．しかし、これらの曲線の変位が小 さい部分の直線近似した時の傾きと最大荷重値を比 較すると， $2000^{\circ} \mathrm{C}$ で焼結した複合体の方が， $1950^{\circ} \mathrm{C}$ で焼結した複合体より，大きかった。この結果は， $2000^{\circ} \mathrm{C}$ で烧結したSiC.C $\mathrm{C}_{1} / \mathrm{SiC}$ 複合体の方が, $1950^{\circ} \mathrm{C}$ で焼結したSiC·C $1 / \mathrm{SiC}$ 複合体に比へ，より瀻維の赤 強効果が大きいことを示している．これは，炭素緎 維の表面にSiCを被覆することにより，C／／SiC複合 体の作製時に見られた高温姺結条件での織維劣化を 低減できること及び，高温焼秸では織維とマトリッ クス界面が強く結合できること等の理由により，強 く結合した界面を介して高強度な織維の特性が引出 、せたためと考えられる。 


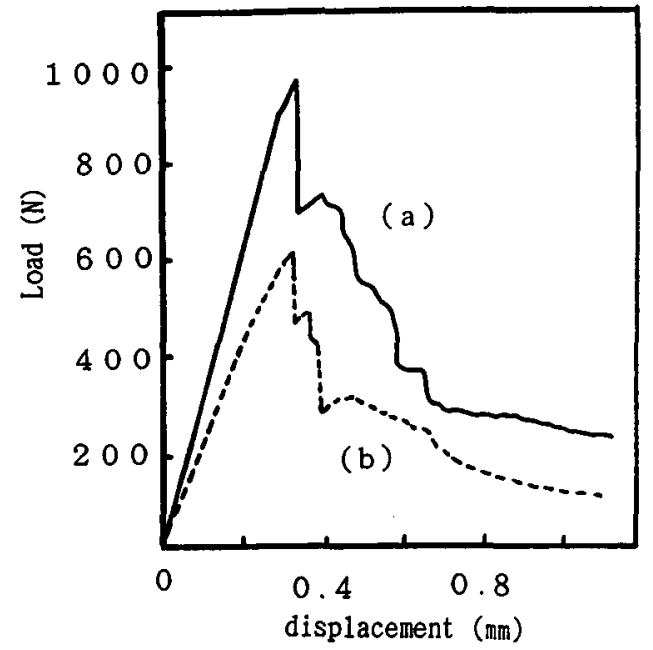

Fig. 2 Load-displacement curves of $\mathrm{SiC} \cdot \mathrm{C}_{t} / \mathrm{SiC}$ composite obtained by 3 point bending test.

(a) sintered at $2000^{\circ} \mathrm{C}$

(b) sintered at $1950^{\circ} \mathrm{C}$

\section{3. $2 \mathrm{SiC}$ 被覆之機械特性の関係}

\section{2 .1 機械特性}

\section{$\mathrm{C}_{\mathrm{f}} / \mathrm{SiC}$ 複合体の機械特性に及ぼす炭素維維への}

$\mathrm{SiC}$ 被覆の影響について検討するため, $\mathrm{SiC} \cdot \mathrm{C}_{f} / \mathrm{SiC}(2$ $000^{\circ} \mathrm{C}$ 锛結）とC $\mathrm{C}_{t} / \mathrm{SiC}\left(1950^{\circ} \mathrm{C}\right.$ 焼結) の曲げ強度，破 壊鞋性および破壊エネルギーを比較した。

Table 2 Characteristic and mechancal properties of $\mathrm{SiC} \cdot \mathrm{C}_{\mathrm{f}} / \mathrm{SiC}$ and $\mathrm{C}_{t} / \mathrm{SiC}$ composites.

\begin{tabular}{|l|r|r|r|}
\hline \multicolumn{2}{|c|}{ Characteristics } & $\mathrm{C}_{1} / \mathrm{SiC}$ & $\mathrm{SiC} \cdot \mathrm{C}_{1} / \mathrm{SiC}$ \\
\hline \multicolumn{2}{|c|}{ Open Porosity (\%) } & 4 & 6 \\
\hline \multicolumn{2}{|c|}{ Fiber Content (\%) } & 56 & 56 \\
\hline $\begin{array}{c}\text { Flexural } \\
\text { strength } \\
\text { (MPa) }\end{array}$ & Room temp. & 950 & 540 \\
\cline { 2 - 5 } & $1450^{\circ} \mathrm{C}$ & 1050 & 720 \\
\hline $\begin{array}{c}\text { Fracture Toughness }\left(\mathrm{MPa} \cdot \mathrm{m}^{1 / 2}\right) \\
\text { Fracture Energy }\left(\mathrm{J} / \mathrm{m}^{2}\right)\end{array}$ & 9000 & 21500 \\
\hline \multicolumn{2}{|l|}{ Fractury } \\
\hline
\end{tabular}

Table 2 より， $\mathrm{SiC} \cdot \mathrm{C}_{t} / \mathrm{SiC}$ 複合体の曲げ強度は， $\mathrm{C}_{t} /$ $\mathrm{SiC}$ 複合体の曲げ強度に比へ，常温強度，高温強度 ともに低かった，また、破壊鞄性についても同様の 傾向が見られた。 一方, $\mathrm{SiC} \cdot \mathrm{C}_{1} / \mathrm{SiC}$ 複合体の破壊 エネルギーは，曲げ強度等に見られる㑯向とは異な り, $\mathrm{C}_{t} / \mathrm{SiC}$ 複合体に比べて高かった.

これらのことから， $\mathrm{SiC}$ 膜を被覆した炭素織維を 用いて襩合体を作製すると，得られる複合体の曲げ
強度や破壊靱性は低下するが，破壊エネルギーは逆 に增加することが分かった，さらに，SiC被徣の破 罣エネルギーに及ぼす影響を詳しく調べるため, $\mathrm{SiC} \cdot \mathrm{C}_{\mathrm{f}} / \mathrm{SiC} と \mathrm{C}_{\mathrm{f}} / \mathrm{SiC}$ 複合体の荷重一変位曲線につい て検討した．Fig.3に，両複合体の荷重一变位曲線 を示す.

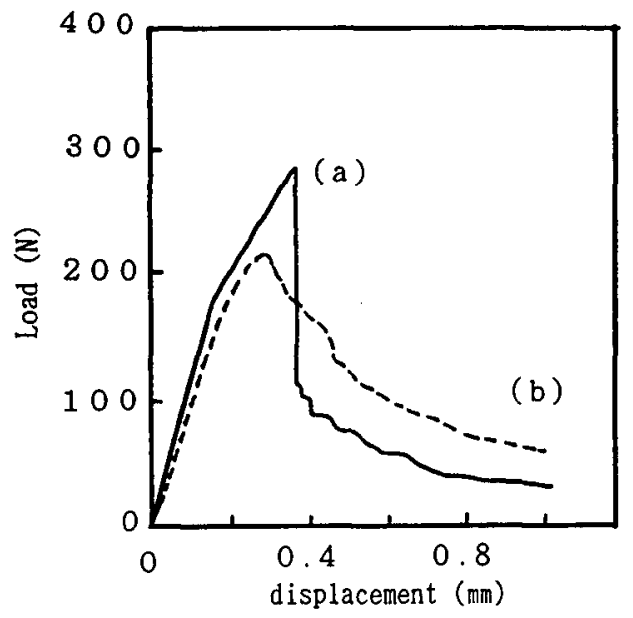

Fig. 3 Load-displacement curves obtained by fracture energy measurement.
(a) $\mathrm{C}_{t} / \mathrm{SiC}$ composite
(b) $\mathrm{SiC} \cdot \mathrm{C}_{1} / \mathrm{SiC}$ composite

Fig.2より， $\mathrm{C}_{1} / \mathrm{SiC}$ 複合体の荷重一变位曲線 における最大負荷荷重点は, $\mathrm{SiC} \cdot \mathrm{C}_{\mathfrak{l}} / \mathrm{SiC}$ 複合 体の最大負荷荷重点より高い.これが, $C_{t} /$ $\mathrm{SiC}$ 複合体の破罗靬性かi $\mathrm{SiC} \cdot \mathrm{C}_{1} / \mathrm{SiC}$ 複合体の 破罗靱性より高くなる理由である，またFig. $3 の C_{t} / \mathrm{SiC}$ 複合体の荷重一変位曲線では，変 位が最大負荷荷重点を越えると，急激な荷重 低下を示すのに対して, $\mathrm{SiC} \cdot \mathrm{C}_{\mathrm{f}} / \mathrm{SiC}$ 複合体の 荷重一変位曲線では，变位が最大負荷荷重点 を越えても荷重低下は，楥やかである，両曲 線の比較から，岑素瀻維にSiC膜を被椱する ことにより，最大負荷荷重は低下するものの， 最大負荷荷重点を越えてからの荷重一变位曲線の急 激な荷重低下を低減できた。この結果，变位軸と荷 重一変位曲線の囲む面積である破艢仕事量は，SiC. $\mathrm{C}_{t} / \mathrm{SiC}$ 複合体の方が大きくなる。これより，SiC膜 被玫により破壊エネルギー值が增加したのは， $C_{1} /$ $\mathrm{SiC}$ 複合体にみられる荷重一変位曲線の急激な荷重 低下がSiC·Cl $/$ SiC複合体で見られなくなったためと 考えられる，なお，SiC被覆により，破壊仕事が增 
加する原因については，3.2.2の破面における織維 /マトリックス界面の観察により検討する.

\section{2.2 織維/マトリックス界面}

Photo.1に曲げ試験後のSiC.C $C_{t} / \mathrm{SiC}_{\text {jよび }} / \mathrm{SiC}$ 複合体の破面の走查型電子顕微鏡写真を示す.

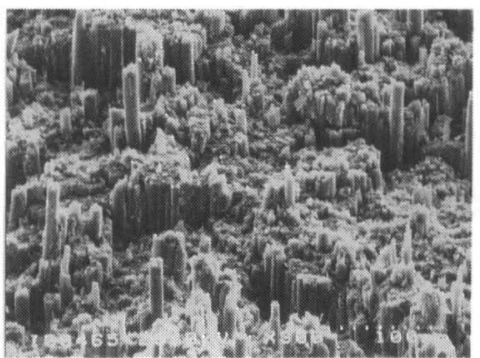

(a)

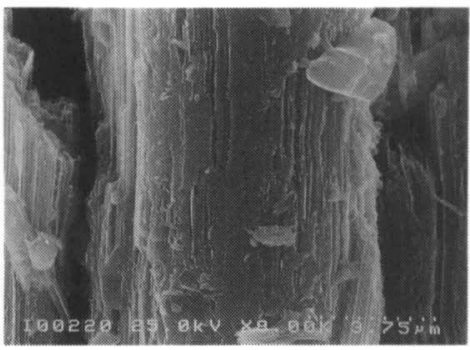

(c)

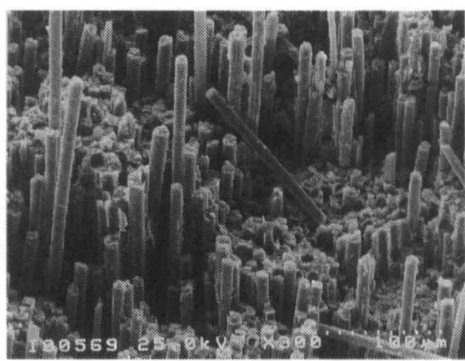

(b)

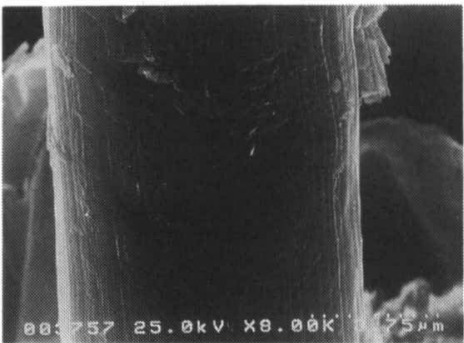

(d)

Photo.1 SEM photographs of fracture surface of $\mathrm{C}_{t} / \mathrm{SiC}$ and $\mathrm{SiC} \cdot \mathrm{C}_{t} / \mathrm{SiC}$ composites.

$\begin{array}{ll}\text { (a) } \mathrm{C}_{t} / \mathrm{SiC} & \text { (c) } \mathrm{C}_{t} \text { surface pulled out from } \mathrm{C}_{t} / \mathrm{SiC}\end{array}$

(b) $\mathrm{SiC} \cdot \mathrm{C}_{t} / \mathrm{SiC}$ (d) $\mathrm{SiC} \cdot \mathrm{C}_{t}$ surface pulled out from $\mathrm{SiC} \cdot \mathrm{C}_{t} / \mathrm{SiC}$

Photo.1の破面部で, 両複合体からの炭素織維の引 き抜け長さを比較すると, $\mathrm{SiC} \cdot \mathrm{C}_{t} / \mathrm{SiC}$ 複合体から引 き抜けた炭素織維の長さは， $\mathrm{C}_{1} / \mathrm{SiC}$ 複合体から引き 抜けた炭素織維より長い。このことは, 炭素織維に $\mathrm{SiC}$ 膜を被覆すると, 織維の引き抜けが容易になる ことを示している．この原因としては， $\mathrm{SiC}$ 膜を被 覆することによって, 複合体作製時に炭素織維が劣 化しにくくなることおよび複合体の界面强度が低く なること等が考えられる. そこで, Photo.1で示し た引き抜けた炭素織維表面を拡大し，その表面部の 組織を比較することで, 間接的に, 複合体の界面強 度の違いを検討した。

Photo.1より, $\mathrm{C}_{t} / \mathrm{SiC}$ 複合体から引き抜けた炭素 織維の表面には, 蟣維の一部が削り取られて損傷し た跡が見られる．これに対し， $\mathrm{SiC} \cdot \mathrm{C}_{t} / \mathrm{SiC}$ 複合体か ら引き抜けた炭素織維の表面は, 滑らかであり, 織
$4 \mu \mathrm{m}$
維の一部が削り取られて損傷した跡は見られない。

これらの結果より，両複合体の界面状態の違いを 以下の椂に考察した． 即ち， $\mathrm{C}_{t} / \mathrm{SiC}$ 複合体では，織 維とマトリックスは強く結合しており, 破断に際し て界面の結合を切る為には，大きな力が必要になり， その際織維の一部が削り取られ る. 一方, $\mathrm{SiC} \cdot \mathrm{C}_{\mathrm{t}} / \mathrm{SiC}$ 複合体 では, 緎維とマトリックスとの 結合は, $\mathrm{C}_{\mathrm{t}} / \mathrm{SiC}$ 複合体ほど強固 でない,したがって，破断に際 して界面の結合を切るためには， 織維に損傷を与えるような力を 必要とせず, 織維の一部が界面 の剥離時に削り取られることは ない.

ここで，炭素織維表面へSiC を被覆したときの界面に及ぼす 影響は, 織維/マトリックス界 面の結合強度を弱める働きをす るものと考えられる.

このことは, Photo.2に示し た $\mathrm{SiC} \cdot \mathrm{C}_{\mathrm{t}} / \mathrm{SiC}$ 複合体の破断面の 拡大写真からもわかる. 即ち, Fig. 5 の織維の引抜けた部分を みると，織維を被覆したSiC膜 は, 織維が引き抜ける際マトリ ックス部に残っている。これは，SiC膜が織維より もマトリックス部と強固に結合していることを示し ている.

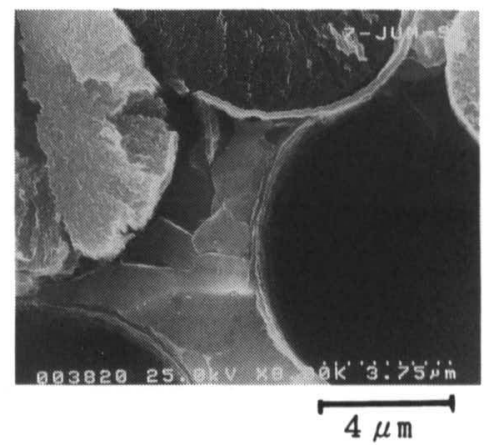

Photo. 2 SEM photographs of fracture surface of $\mathrm{SiC} \cdot \mathrm{C}_{\mathrm{t}} / \mathrm{SiC}$ composites.

この原因について考察する. C $1 /$ SiCのマトリック 
ス中には，Sicのほかに焼結助剤が存在する．この 焼結助剤は，SiCの緻密化を促進するために入れた ものだが，䋐維と反応すれば，マトリックスと織維 との結合を強くする働きも考えられる，しかるに， 炭素瀻維表面をSiC膜で被覆すると，焼結助䬉は， 炭素㵶維と接触できない，その結果， $\mathrm{SiC}$ 膜によっ て縕維とマトリックスとの反応が扣制され，㵶維と マトリックス界面の結合強度は，SiC膜で被覆しな い場合に比へ低下する，複合材料では，㵶維強度 及び繊維とマトリックスとの接着強度が強固である ほよ゙，より大きい荷重負担にたえられるが，繊維よ マトリックスとの接着強度が弱い場合には，大きな 荷重負担にたえられない。

したがって，界面の結合強度が低いSiC・C $\mathrm{f} / \mathrm{SiC}$ 複 合体では， $\mathrm{C}_{1} / \mathrm{SiC}$ 複合体より低い曲げ強度を示すは ずである. Table 2 でC $\mathrm{f} / \mathrm{SiC}$ 複合体の曲げ強度がSiC・ $\mathrm{C}_{1} / \mathrm{SiC}$ 複合体の曲げ強度に比べ大きな值を示すのは， 本推論を支持しているものと考えられる，また，Si Cで被覆しても炭素繊維強度は低下しないことから， 繊維/マトリックス界面の結合強度が弱まれば，曲 げ試験時に複合体からの繊維の引き抜けが容易にな るぶん，擮維の引き抜け時により大きな破壊エネル
ギーを吸収することができると思われる，Table 2 に示した， C $/ \mathrm{SiC}$ 複合体の破壊エネルギー值がSiC. $\mathrm{C}_{t} / \mathrm{SiC}$ 複合体の曲げ強度に比べ大きな値を示す測定 結果は，本推論を支持していると思われる.

\section{4 結言}

$\mathrm{SiC}$ 被覆炭素織維強化SiCの強度は, 炭素緎維強化 SiCの強度より低いが，破壊エネルギー值は，逆に 高くなる，この原因は，界面強度の変化であり，炭 素繊維にSiC膜を被覆すると, 繊維と助剤成分との 反応が抑制され，界面の結合が弱くなったためであ る。

\section{謝 辞}

本研究は，石油産業活性化センターの委託研究の一 部として実施したものである.

\section{文 献}

1）吉田秀人，宮田昇，内藤一成，山岸干丈： 粉体および粉末治金，41(1994)揭載予定。

2）吉田秀人，宮田昇，佐川雅昭，石川繁樹, 山岸千丈：粉体および粉末治金，39(1992)1055。 